\title{
APLIKASI SISTEM ADMINISTRASI PADA LES BAHASA ARAB RUMAH DAKWAH MULIA
}

\author{
Sifa Fauziyah ${ }^{1}$, Julizal ${ }^{2}$ \\ ${ }^{1,2}$ Universitas Indraprasta PGRI \\ TB. Simatupang, Jl. Nangka Raya No.58 C, RT.5/RW.5, TJ. Barat., Kec. Jagakarsa, Kota Jakarta Selatan \\ Daerah Khusus Ibukota Jakarata 12530 \\ 10shimasyifa46@gmail.com, ${ }^{2 j u l i z a l . r a m @ g m a i l . c o m ~}$
}

\begin{abstract}
ABSTRAK
Bahasa yang terkandung dalam Al-Qur'an merupakan Bahasa Arab. Hal ini menyebabkan Bahasa Arab identik dengan Agama Islam. Namun kini mulai banyak ditinggalkan dan digantikan dengan Bahasa Eropa, seperti Bahasa Inggris dan Perancis. Karenanya, berbagai pihak mulai menyadari dan melakukan berbagai gerakan guna mengembalikan kejayaan Bahasa Arab. Maka dari itu, dibentuklah lembaga kursus Bahasa Arab. Salah satunya lembaga kursus Bahasa Arab di kota Bekasi adalah Rumah Dakwah Mulia. Saat ini administrasi Rumah Dakwah Mulia masih mengadopsi sistem manual. Oleh karenanya, penulis berupaya memberikan solusi dengan mengembangkan dan mengaplikasikan alur kerja sistem administrasi yang mampu memproses data secara cepat dan akurat. Penulis bermaksud membuat suatu aplikasi dengan tujuan merancang sistem administrasi yang dapat digunakan oleh admin. Dengan menggunakan metode Waterfall dan metode $R \& D$ (Research and Development). Dengan menggunakan metode tersebut, didapatkan hasil sebagai berikut : Aplikasi administrasi yang telah dibuat dapat mempermudah admin dalam mengelola data pada Rumah Dakwah Mulia, sistem ini dapat mengelola dan memproses penginputan seluruh data yang ada pada Rumah Dakwah Mulia dengan cepat dan tepat, dan dapat mempermudah dalam pembuatan laporan, serta pencetakan sertifikat untuk siswa yang memenuhi standar penilaian pada Rumah Dakwah Mulia.
\end{abstract}

Kata Kunci: Aplikasi Siistem Administrasi, Administrasi, Sistem.

\begin{abstract}
The language contained in the Qur'an is Arabic. This causes Arabic to be synonymous with Islam. But now many are being abandoned and replaced by European languages, as well as English and French. Therefore, various parties began to realize and carry out various movements to restore the glory of the Arabic language. Therefore, an Arabic language course institute was formed. One of the Arabic language course institutions in the city of Bekasi is Rumah Dawah Mulia. Currently, the administration of Rumah Da'wah Mulia is still adopting a manual system. Therefore, the author seeks to provide a solution by developing and applying an administrative system workflow that is able to process data quickly and accurately. The author intends to create an application with the aim of designing an administrative system that can be used by admins. Using waterfall method and $R \& D$ (Research and Development) method. Using this method, the following results are obtained: Administrative applications that have been made can make it easier for admins to manage data at Rumah Dawah Mulia, this system can manage and process the input of all data in the House of Dawah Mulia quickly and precisely, and can facilitate in the creation of reports, as well as the printing of certificates for students who meet the assessment standards at Rumah Dawah Mulia.
\end{abstract}

Key Word: Administration System Application, Administration, System.

\section{PENDAHULUAN}

Rumah Dakwah Mulia merupakan lembaga program Bahasa Arab. Rumah Dakwah Mulia menjadi lembaga Bahasa Arab yang mampu memberikan solusi kepada masyarakat muslim dan masyarakat umum untuk memahami Islam dengan benar melalui bahasa aslinya. Bahasa merupakan alat komunikasi dan penghubung dalam berinteraksi manusia sehari-hari baik antara individu dengan individu maupun individu dengan masyarakat. (Hermawan 2011). Namun pelayanan administrasi Rumah Dakwah Mulia masih menggunakan sistem manual, terlihat dari pendataan peserta, pemesanan kelas, dan pembayaran dicatat pada lembaran kertas menggunakan tulisan tangan dan disimpan pada map (snell helder), sehingga menyebabkan penumpukan kertas dan kurangnya integritas data. Aplikasi merupakan penerapan, menyimpan sesuatu hal, data, permasalahan, pekerjaan kedalam 
suatu sarana atau media yang dapat digunakan untuk menerapkan atau mengimplementasikan hal atau permasalahan yang ada sehingga berubah menjadi suatu bentuk yang baru tanpa menghilangkan nilainilai dasar dari hal data, permasalahan, dan pekerjaan itu sendiri. (Jogiyanto 2013). Aplikasi adalah program siap pakai yang dapat digunakan untuk menjalankan perintahperintah dari pengguna aplikasi tersebut dengan tujuan mendapatkan hasil yang lebih akurat sesuai dengan tujuan pembuatan aplikasi tersebut, aplikasi mempunyai arti yaitu pemecahan masalah yang menggunakan salah satu teknik pemrosesan data aplikasi yang biasanya berpacu pada sebuah komputansi yang diinginkan atau diharapkan maupun pemrosesan data yang diharapkan. Pengertian aplikasi secara umum adalah alat terapan yang difungsikan secara khusus dan terpadu sesuai kemampuan yang dimilikinya, aplikasi merupakan suatu perangkat komputer yang siap pakai bagi user. (Abdurahman dan Riswaya 2014).

Berdasarkan kasus tersebut, sehingga Rumah Dakwah Mulia memerlukan suatu sistem data administrasi yang dapat mengolah data murid, guru, dan paket belajar, serta laporan pembayaran spp murid dan mencetakan sertifikat kelulusan, serta menanggulangi masalah-masalah yang terdapat pada Rumah Dakwah Mulia. Dengan ini penulis membuat Rancangan Aplikasi Sistem Administrasi Pada Les Bahasa Arab Rumah Dakwah Mulia diharapkan memudahkan admin untuk meningkatkan pelayanan kepada murid serta menciptakan laporan-laporan.

Sistem bisa diartikan sebagai sekumpulan sub sistem, komponen ataupun element yang saling bekerja sama dengan tujuan yang sama untuk menghasilkan output yang sudah ditentukan sebelumnya. (Prof. Dr. Sri Mulyani, Ak. 2016). Basis data (database) merupakan kumpulan data yang saling berhubungan atau punya relasi. (Vico 2014). Data Flow Diagram atau dalam bahasa Indonesia menjadi Diagram Alir Data (DAD) adalah refresentasi grafik yang menggambarkan aliran informasi dan transformasi informasi yang diaplikasikan sebagai data yang mengatur dari masukan (input) dan keluaran (output). (Sukamto, R.A dan Salahudin 2014). ERD adalah sebuah pendekatan Top-bottom dalam perancangan basis data yang dimulai dengan mengidentifikasikan data-data terpenting yang disebut entitas. (Indrajani 2015). Java adalah bahasa pemrograman yang dapat dijalankan di berbagai komputer termasuk telepon genggam. (Maya 2015). MySQL adalah nama database server. Database server adalah server yang berfungsi untuk menangani database. Database adalah suatu pengorganisasian data dengan tujuan memudahkan penyimpanan dan pengaksesan data. Dengan menggunakan $M y S Q L$, kita bisa menyimpan data dan kemudian data bisa diakses dengan cara yang mudah dan cepat. (Kadir 2013).

Tujuan penelitian ini ialah membuat aplikasi sistem administrasi yang dapat mengolah data antara lain proses mengolah data murid, data guru, paket belajar, dan pembayaran. Serta pembuatan laporan-laporan data antara lain laporan data siswa, data guru, pembayaran, serta sertifikat kelulusan.

\section{METODE PENELITIAN}

Penelitian ini menggunakan metode R\&D (Reseach and Development). Metode R\&D ini seringkali digunakan sebagai proses penelitian yang bertujuan untuk menghasilkan produk, yang langkah-langkahnya adalah analisis, perancangan, penerapan, dan pemeliharaan. (Kristanto 2013).

Metode yang digunakan pengumpulan data serta pengambilan keterangan yang dibutuhkan untuk merancang program dalam penelitian ini dilakukan dengan cara :

\section{Sumber Data Primer}

Data Primer, data berupa catatan dari hasil wawancara dengan informan yang dijadikan sampel penelitian. penulis mengumpulkan data primer dengan menggunakan teknik, antara lain sebagai berikut

1. Observasi (Pengamatan)

Pengamatan dilakukan dengan mengamati langsung dengan kunjungan ke Rumah Dakwah Mulia. Adapun pengamatan dilakukan pada hari biasa dan hari libur. 
Penulis juga melakukan observasi pada admin dari Rumah Dakwah Mulia.

2. Wawancara

Wawancara dilakukan dengan teknik lisan. Dalam hal ini yang dijadikan informan yaitu admin dari Rumah Dakwah Mulia. Bertujuan untuk mendapatkan data akurat mengenai Rumah Dakwah Mulia serta mencari pernyataan tentang hal apa yang mendorong untuk melakukan perancangan Aplikasi Sistem Administrasi pada Les Bahasa Arab Rumah Dakwah Mulia.

3. Dokumentasi

Mengumpulkan data dengan cara mencatat semua data yang ada pada dokumen atau arsip Rumah Dakwah Mulia.

\section{Sumber Data Sekunder}

Teknik pengumpulan data dengan cara studi pustaka yaitu, mengumpulkan data dan mempelajari beberapa jurnal dan catatancatatan kuliah yang berhubungan dengan permasalahan yang akan diteliti.

Dalam pengembangan sistem yang terdapat pada Rumah Dakwah Mulia, penulis menggunakan metodologi waterfall. Proses yang dilalui dalam mengembangkan sistem diurutkan sesuai dengan kepentingan, yakni dimulai dari tahap Requirement atau analisis data, kemudian tahap desain, implementasi, Verification atau pengujian dan Maintenance atau pemeliharaan (Erri Wahyu Puspitarini 2016).

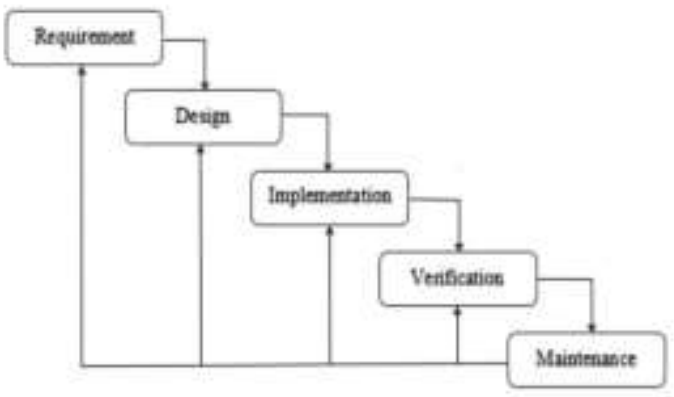

Gambar 1. Metode Waterfall

\section{HASIL DAN PEMBAHASAN}

Berdasarkan hasil penelitian kasus sebelumnya, peneliti menaruh analisa konflik berdasarkan sistem pengelolaan data diantaranya :

1. Membuat Rancang Bangun Aplikasi Sistem Administrasi Pada Les Bahasa Arab Rumah Dakwah Mulia untuk mempermudah dalam menyusun dan mengolah semua laporan yang berkaitan dengan administrasi dengan baik dan akurat.

2. Menggunakan database MySQL, sebagai media penyimpanan data agar data dapat disimpan dengan aman dan tidak terjadi kehilangan data.

3. Menggunakan iReport pada netbeans, agar pembuatan laporan lebih efektif dan efisien. Penggunaan iReport juga mengurangi terjadinya kesalahan pada pembuatan laporan.

Kamus data adalah kumpulan daftar elemen data yang mengalir pada sistem perangkat lunak sehingga masukan (input) dan keluaran (output) dapat dipahami secara umum (memiliki standar cara penulisan). (Sukamto, R.A dan Salahudin 2014).I

\section{Diagram Konteks Sistem}

Berikut ialah gambaran sistem pada rancang bangun aplikasi sistem administrasi pada les bahasa Arab Rumah Dakwah Mulia dalam bentuk diagram konteks.

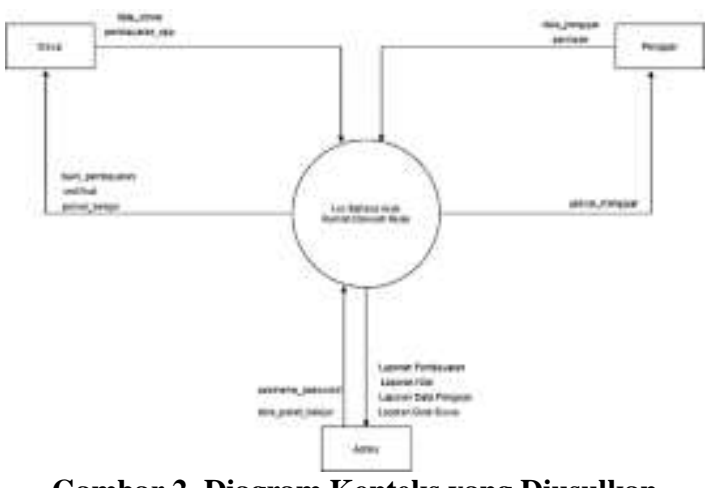

Gambar 2. Diagram Konteks yang Diusulkan

(ERD) Entity Relationship Diagram

ERD adalah sebuah pendekatan Top-bottom dalam perancangan basis data yang dimulai dengan mengidentifikasikan data-data terpenting yang disebut entitas. (Indrajani 2015). 


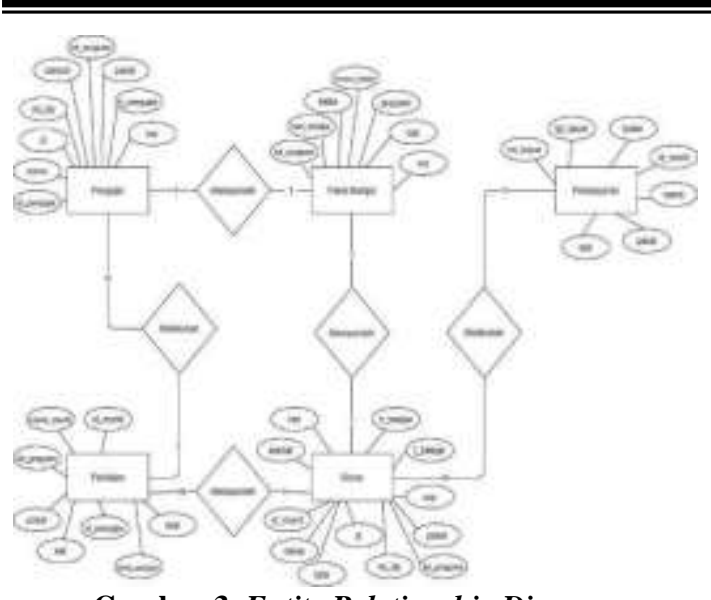

Tampilan Layar

Dari pembahasan diatas, maka penulis dapat merangkumnya dan menjadikannya suatu aplikasi yang dapat membatu di rumah dakwah mulia saat ini, diantaranya adalah :

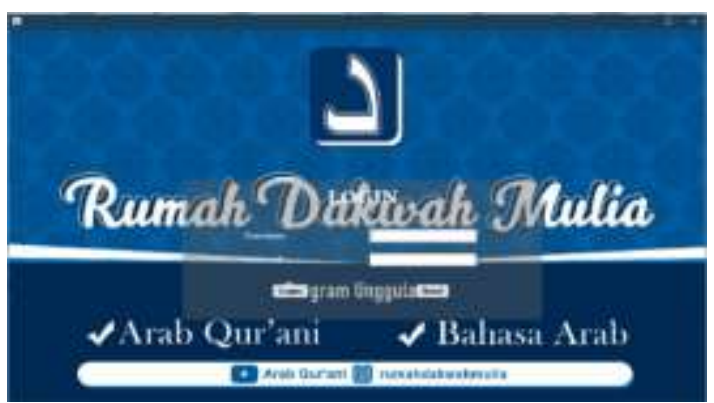

Gambar 3. Tampilan Login

Tampilan menu login merupakan tampilan awal program ketika membuka program. Masukkan username dan password untuk melakukan akses sebelum masuk ke menu utama serta menu-menu yang terdapat pada sistem.

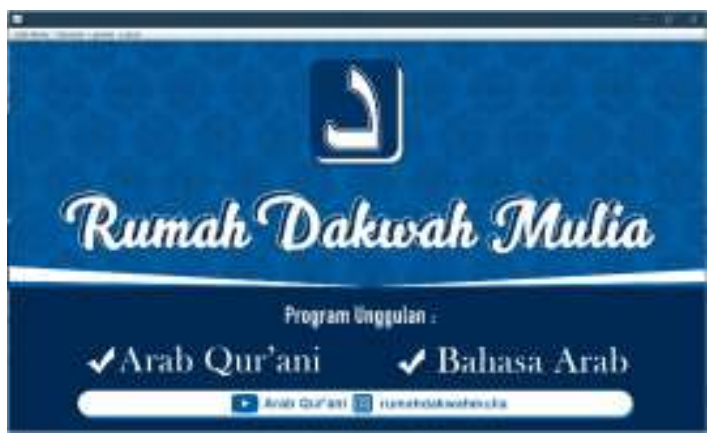

Gambar 4. Tampilan Menu Utama

Tampilan menu utama dari sistem yang dirancang adalah untuk memilih menu sesuai dengan kegiatan proses pekerjaan yang dibutuhkan.

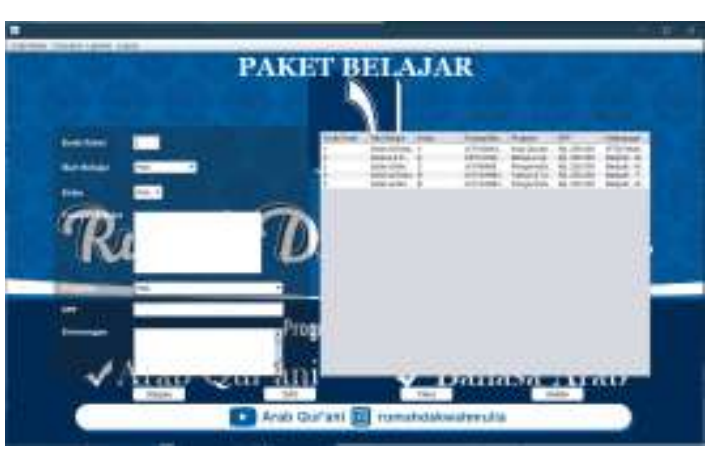

Gambar 5. Tampilan Form Paket Belajar

Tampilan menu form paket belajar digunakan untuk menambahkan ataupun mengurangi paket belajar yang ada di Rumah Dakwah Mulia.

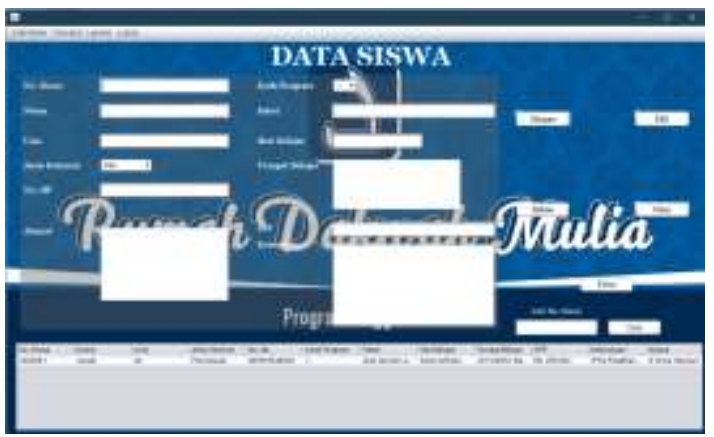

Gambar 6. Tampilan Form Data Siswa

Tampilan form data siswa digunakan untuk mendata pendaftaran siswa.

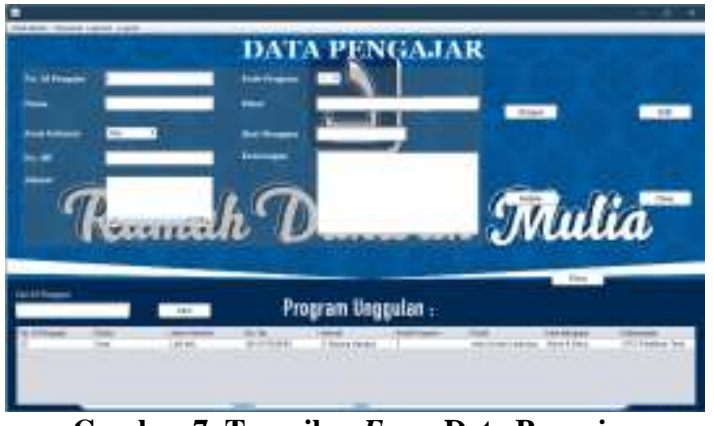

Gambar 7. Tampilan Form Data Pengajar

Tampilan form data pengajar digunakan untuk mendata pengajar.

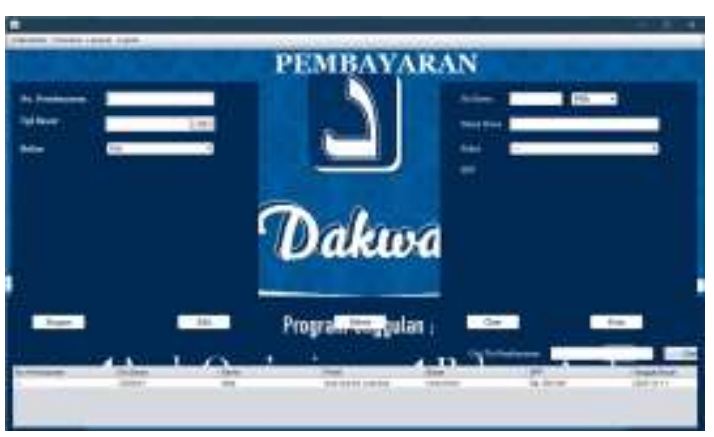

Gambar 8. Tampilan Form Pembayaran 
Tampilan form pembayaran digunakan untuk mendata pembayaran spp siswa.

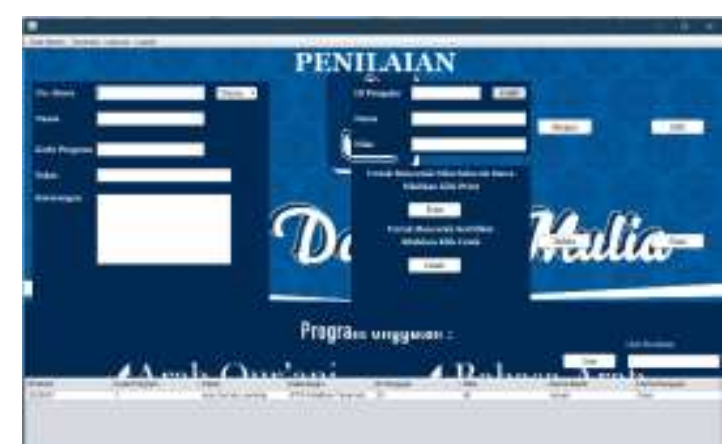

Gambar 9. Tampilan Form Penilaian

Tampilan form penilaian digunakan untuk mendata hasil penilaian siswa.

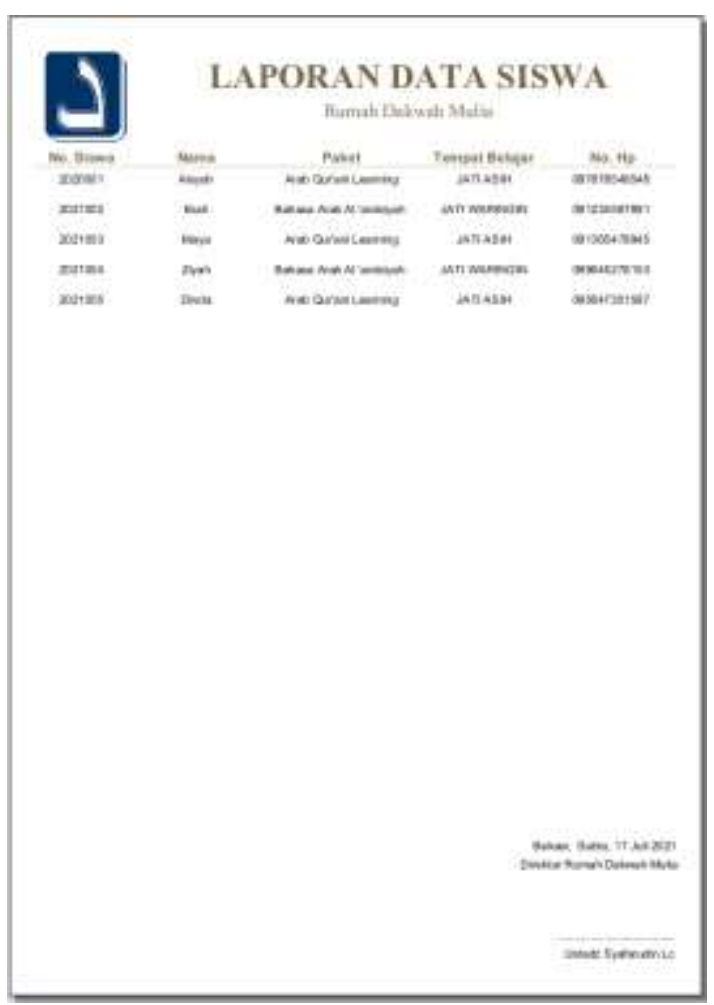

Gambar 10. Tampilan Lampiran Data Siswa

Tampilan diatas merupakan tampilan form data siswa yang akan dijadikan laporan data siswa.

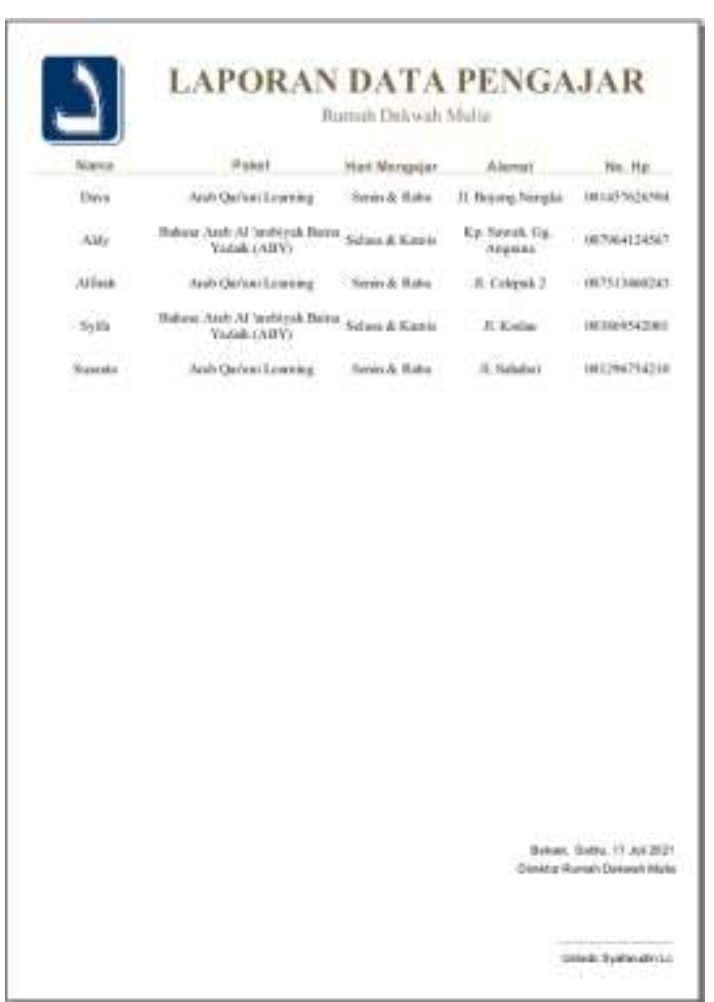

Gambar 11. Tampilan Laporan Data Pengajar

Tampilan diatas merupakan tampilan form data pengajar untuk dijadikan laporan data pengajar.

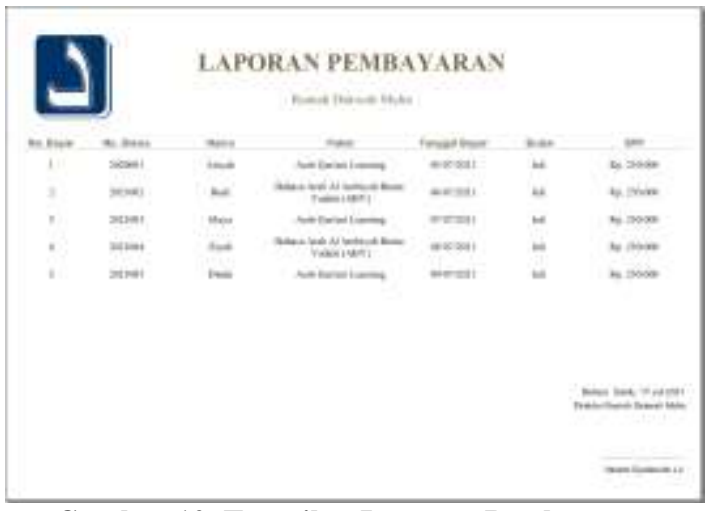

Gambar 12. Tampilan Laporan Pembayaran

Tampilan diatas merupakan tampilan form data pembayaran yang akan dijadikan laporan data pembayaran semua siswa. 


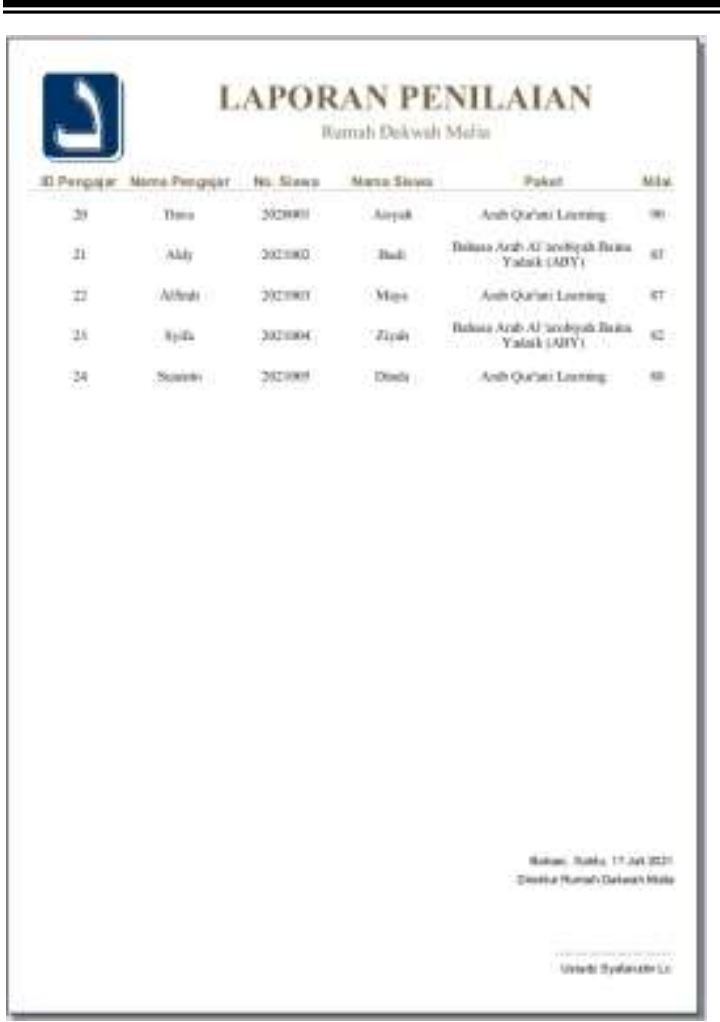

Gambar 13. Tampilan Laporan Penilaian

Tampilan diatas merupakan tampilan form data penilaian yang akan dijadikan laporan data penilaian semua siswa.

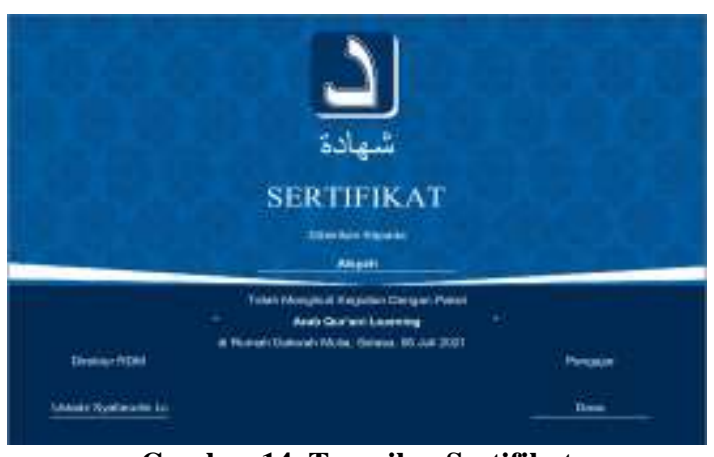

Gambar 14. Tampilan Sertifikat

Tampilan diatas merupakan tampilan form data siswa yang akan dijadikan laporan sertifikat bagi siswa yang lulus.

\section{SIMPULAN DAN SARAN}

Sistem Aplikasi Administrasi di Rumah Dakwah Mulia menjadi salah satu solusi dalam melakukan kegiatan yang berhubungan dengan pendataan dan pelaporan yang sebelumnya masih menggunakan cara manual, karena dengan adanya Sistem Aplikasi Administrasi ini, setiap proses pendataan dapat dilakukan secara terkomputerisasi dan terintegerasi dengan database.
Berdasarkan hasil analisis penelitian yag telah dilakukan penulis, dapat diambil beberapa kesimpulan yaitu :

Aplikasi administrasi yang telah dibuat dapat mempermudah karyawan dan pemilik dalam mengelola data pada Rumah Dakwah Mulia. Sistem Aplikasi administrasi ini dapat mengelola dan memproses penginputan seluruh data yang ada pada Rumah Dakwah Mulia dengan cepat dan tepat. Sistem Aplikasi administrasi yang telah dibuat dapat mempermudah dalam pembuatan laporan, serta pencetakan sertifikat untuk siswa yang memenuhi standar penilaian pada Rumah Dakwah Mulia.

\section{DAFTAR PUSTAKA}

Abdurahman, Hasan, and Asep Ririh Riswaya. 2014. "Aplikasi Pinjaman Pembayaran Secara Kredit Pada Bank Yudha Bhakti." Jurnal Computech \& Bisnis 8(2):61-69.

Erri Wahyu Puspitarini, Dian Wahyu Putra, A. Prasita Nugroho,. 2016. "Game Edukasi Berbasis Android Sebagai Media Pembelajaran Untuk Anak Usia Dini." Jurnal Informatika Merdeka Pasuruan 1(1):264570. 10.37438/JIMP.V1I1.7. doi:

Hermawan, Acep. 2011. "Metodologi Pembelajaran Bahasa Arab / Acep Hermawan; Pengantar, Chaidar Alwasilah; Editor, Anang Solihin Wardan | OPAC Perpustakaan Nasional RI." Retrieved August 12, 2021 (https://opac.perpusnas.go.id/DetailOpa c. aspx?id=48061).

Indrajani. 2015. "Database Design - Google Books." Retrieved August 12, 2021 (https://www.google.co.id/books/editio n/Database_Design/Lk5JDwAAQBAJ? $\mathrm{hl}=\mathrm{en} \& \mathrm{gbpv}=1 \& \mathrm{dq}=$ Database + Design + 2015\&printsec $=$ frontcover).

Jogiyanto. 2013. Analisis \& Desain Sistem Informasi: Pendekatan Terstruktur Teori Dan Praktik Aplikasi Bisnis. Yogyakarta: Andi Offset.

Kadir, Abdul. 2013. Pemrograman Database MySQL Untuk Pemula. Yogyakarta: Mediakom.

Kristanto, Andri. 2013. "Perancangan Sistem Informasi Dan Aplikasinya."

Maya. 2015. "Membangun Sistem Informasi Dengan Java NetBeans Dan MySQL: Panduan Aplikasi \& Solusi (PAS) / 
Editor, Maya | OPAC Perpustakaan Nasional RI." Retrieved August 12, 2021

(https://opac.perpusnas.go.id/DetailOpa c. $\operatorname{aspx}$ ?id=952545).

Prof. Dr. Sri Mulyani, Ak., CA. 2016. "Metode Analisis Dan Perancangan Sistem - Prof. Dr. Sri Mulyani, Ak., CA. - Google Books." Retrieved August 12, 2021

(https://books.google.co.id/books?hl=en $\& 1 \mathrm{r}=\& \mathrm{id}=$ SbrPDgAAQBAJ $\&$ oi $=$ fnd $\& p$ $\mathrm{g}=\mathrm{PP} 1 \&$ ots=fo6ZiKK0qO\&sig=uMzIk 5ZgE2kcUkYIbSUL2LyYqOQ\&redir_ $\mathrm{esc}=\mathrm{y} \# \mathrm{v}=$ onepage $\& \mathrm{q} \& \mathrm{f}=$ false).

Sukamto, R.A dan Salahudin, M. 2014. Rekayasa Perangkat Lunak Terstruktur Dan Berorientasi Objek. Bandung: Informatika Bandung.

Vico, Hisbanarto \&. Yakub. 2014. "Sistem Informasi Manajemen Pendidikan/ Yakub, Vico Hisbanarto | OPAC Perpustakaan Nasional RI." Retrieved August $\quad 12, \quad 2021$ (https://opac.perpusnas.go.id/DetailOpa c. aspx?id=951106). 